checked. Nevertheless, it is a practical means of keeping cider below the 0.5 per cent alcoholic limit, and the beverage thus treated could be safely dispensed until too sour to be palatable. The addition of 0.05 per cent, of the preservative to the fresh juice should be sufficient.

While salicylic acid is not considered more harmful than other preservatives, ${ }^{1}$ it has not been received with much favor. It would probably have to be used to the extent of 0.1 per cent, an amount probably somewhat too high to be desirable from a physiological standpoint. However," it should be mentioned that tests described in the above reference show only a slight ill effect from the ingestion of 1 g. per day for 30 days.

\section{CoNClustons}

1 -Salicylic acid 0.2 per cent or thymol 0.1 per cent will preserve cider effectively for the purpose of court work.

2-For preserving cider commercially, sodium benzoate and salicylic acid are of some value.

\title{
A New Qualitative Test for Sucrose in the Presence of Glucose ${ }^{2}$
}

\section{By Leon A. Congdon and Charles R. Stewart}

DEPARTMENT OF CHEMTSTRY, SYRACUSE UNIVERSITY, SYRACUSE, NEW YORK

Comparatively few qualitative tests for sucrose in the presence of glucose have been developed, for attention has been directed more especially to their quantitative estimation. The determination of specific rotation or reducing power before and after inversion with hydrogen chloride or invertase has been of value in the past as a means of identification. In considering the specific rotation of mixtures of sucrose and glucose in a compound of unknown composition, we must not lose sight of the fact that foreign optically active substances would influence this value. In selecting the reduction method, it must be taken into account that there is a slight reduction of copper by sucrose in the presence of invert sugar. ${ }^{3}$

In the color reactions with phenols in presence of concentrated acid, used for the identification of sugars, the development of the color is said to be due to the formation of condensation products between the phenol derivatives and the decomposition products obtained from the sugar (humus substances, furfural, aldehydes, etc.). The most important phenol derivatives used for color reactions with sugars are $\alpha$-naphthol, thymol, resorcinol, orcinol, naphthoresorcinol, and phloroglucinol.

The $\alpha$-naphthol method described by Rapp and Reseinfelder ${ }^{4}$ and others ${ }^{5}$ is extremely delicate for sucrose solutions, but, according to C. A. Browne, ${ }^{6}$ the deep violet coloration is also given by solutions of invert sugar. The tints given by other phenol derivatives vary from cherry-red to deep purple. The coloration which sucrose gives with morphine, codeine, aconitine, veratrine, and other alkaloids, in presence of sulfuric acid is also given by invert sugar, the same being true for the coloration given with ammonium molybdate ${ }^{7}$ in presence of sulfuric acid.

C. Reichard ${ }^{8}$ has suggested the use of sodium arsenate or tannic acid in the presence of hydrogen chloride for the detection of sucrose, but the value of this test is undetermined as vet. The work of Reichard upon the reactions of carbohydrates showed that, in the cold, sulfuric, nitric, or hydrochloric acid converted sugar into a pasty mass, which did not dry in the air. Carbonaceous matter produced by the sulfuric acid did not separate until the mixture was heated. The green coloration of copper sulfate in hydrochloric acid was retained much longer when sucrose was present, and it inhibited somewhat the precipitation produced by the acid when added to mercurous nitrate. In the presence of hydrochloric acid, sucrose yielded a dark green coloration

i U. S. Bureau of Chemistry, Bulletin 8A, II, 757.

2 Received June 9, 1921.

- G. L. Spencer, "Handbook for Cane Sugar Manufacturers and Their Chemists," J. Wiley \& Sons, 1912, 91.

4 Deut. Zuckerind., 1892, 538.

Monatsh., 6 (1885), 198; abstr. J. Chem. Soc., 50 (1886), 923.

" "Handbook of Sugar Analysis," J. Wiley \& Sons, 1912, 681.

'Bull. assoc. chim. sucr. dist, 27 (1909), No 3, 179; abstr. Chom.-Ztg., 33 (1909), 538.

8 Pharm. Zentralhalle, 51 (1910), 979; abstr. J. Chem. Soc., 98 (1910), 1117 ; abstr. Expt. Sta. Record, 25, No. 9, 801. with potassium bichromate, a blue with ammonium molybdate, and a brown which changed to violet with ammonium vanadate. No coloration was produced with sodium tungstate or titanic acid in the presence of sulfuric acid. Sodium arsenate and hydrochloric acid gave a rose-red coloration with sucrose. Of the colorations produced with organic bodies, the most marked was the red with tannic acid in the presence of hydrochloric acid. The author points out the value of this tannic acid test, the resorcinol color test, and the arsenic acid reaction for the detection of sucrose.

Wiley ${ }^{1}$ has suggested a qualitative test for sucrose in the presence of glucose. The sugar is treated with cobaltous nitrate and potassium hydroxide, after dextrin or gums have been removed with alcohol. Sucrose will produce a permanent amethyst-blue color while glucose will give a turquoise blue, passing over to a light green. In a mixture of these two sugars, the color due to sucrose will predominate, if not less than 10 per cent of the sucrose is present.

To discover a new method for the qualitative detection of sucrose, a study of the action of various organic solvents upon glucose and sucrose was made.

\section{EXPERIMENTAL}

The substances tested were sucrose and glucose whose impurities were less than 1 per cent. The reagents used for extraction were $n$-amyl alcohol, benzene, toluene, $p$-xylene, carbon bisulfide, ligroin, carbon tetrachloride, acetic acid, acetone, and ethyl acetate. No work was done with methanol, ethyl alcohol, ether, and chloroform, since their action has been thoroughly investigated and it has been found that sucrose and glucose are both insoluble in ether and chloroform, soluble in varying degrees in ethyl alcohol, and insoluble in methanol. The solvents had been redistilled and only those portions which boiled at the temperatures given in the accompanying table were employed in the experiments. A known weight ( $1 \mathrm{~g}$.) of the sugar was taken, and the volume of the solvents used was $100 \mathrm{cc}$.

\begin{tabular}{|c|c|c|c|}
\hline Solvent & BOILINO POINT & $G_{L} U \cos E$ & Sucrost \\
\hline$n$-Amyl alcohol & 137 & Soluble & Soluble \\
\hline $\begin{array}{l}\text { Acetic acid } \\
p \text {-Xylene }\end{array}$ & 118 & Insoluble & Soluble \\
\hline Toluene & 111 & Insoluble & Insoluble \\
\hline Iigroitr & 90 & Insoluble & Insoluble \\
\hline Benzene & 80 & Insoluble & Insoluble \\
\hline Carbon tetrachloride & 76 & Insoluble & Insoluble \\
\hline $\begin{array}{l}\text { Carbon bistulfide } \\
\text { Acetone }^{1}\end{array}$ & $\begin{array}{l}46 \\
56\end{array}$ & $\begin{array}{l}\text { Insoluble } \\
\text { Soluble (vari- }\end{array}$ & $\begin{array}{l}\text { Insoluble } \\
\text { Insoluble (vari- }\end{array}$ \\
\hline Ethyl aceta & 74 & Soluble & Insoluble \\
\hline
\end{tabular}

The dry sucrose and glucose were placed separately in filter paper extraction thimbles. An ordinary Soxhlet extraction tube with reflux condenser, cooled by running water, was used for extraction. A small Bunsen burner was used to bring the organic solvent to the boiling point, and to keep the solvent boiling until the experiment was completed.

1 "Principles and Practice of Agricultural Analysis," III, p. 189, The Chemical Publishing Co., 1908. 
The time of extraction was $5 \mathrm{hrs}$.

The results of these extractions are shown in the table, in which the terms soluble and insoluble are used to show whether or not extraction was possible.

As noted in the table, glucose is almost completely extracted by ethyl acetate while sucrose is but slightly affected. A run was made using equal parts of the glucose and sucrose, duplicating the results already given. Upon cooling the ethyl acetate solution of glucose, crystals of this substance were formed.

Further work is being done to determine the value of ethyl acetate in the quantitative estimation of mixtures of glucose and sucrose, and also on the use of this organic solvent for the actual preparation of crystalline glucose. It is also contemplated to include in this work, mixtures of other sugars, such as fructose and other less common sugars. The effect of traces of water on the solubility of the various sugars in ethyl acetate will also be investigated.

\section{Summary}

1-Ethyl acetate may be used as a reagent for testing a dry mixture of glucose and sucrose by the extraction method, affording a new qualitative test for the separation of glucose and sucrose in mixtures.

2-Further work is being done to determine the value of ethyl acetate in the separation of glucose from other sugars, the separation of sucrose from fructose, etc., the use. of ethyl acetate for the quantitative estimation of the sugars, the use of this solvent in the preparation of crystalline glucose, and the effect of traces of water on the solubility of the various sugars in ethyl acetate.

\title{
Potash Shales of Illinois ${ }^{1}$
}

\author{
By M. M. Austin with S. W. Parr \\ DHPARTMENT OF ChIMISTRY, UNIVERSITY OF IIIINOIS, URBANA, ILIINOIS
}

Investigation of the potash shales of Illinois was taken up in 1917 in an effort to find values in the residues from certain shales which were under investigation in the laboratory of applied chemistry at the University of Illinois, with primary reference to the amount of oil to be obtained on destructive distillation. The shale from one region, Johnson County, yielded from 45 to 50 gal. of oil per ton and would therefore be of interest for its oil yield alone. Other shales which were of questionable value from the standpoint of oil yield might come into the field of possible technical utilization if other values could be discovered in them. This constituted a primary reason for examining all samples for other values, such as phosphorus and potash. The samples, eighteen in all, were furnished through the courtesy of the Illinois State Geological Survey. They came from localities widely distributed over the state. None of the samples contained phosphorus in more than a trace. Although the majority contained 2 or 3 per cent of potash $\left(\mathrm{K}_{2} \mathrm{O}\right)$, which is normal for shale rock, two formations showed a potash content of from 5 to 5.8 per cent $\left(\mathrm{K}_{2} \mathrm{O}\right)$. Of these latter two, the more important is a black carbonaceous shale which outcrops at frequent intervals over a distance of about $7 \mathrm{mi}$. in Union County. The other is a green sandy shale of entirely different character occurring in Lee County near Dixon, Ill.

Potash Shales in Cement Manufacture

From a study of the potash situation it would seem that one of the hopeful sources for a domestic supply resides in the recovery of potash as a by-product from the manufacture of cement... Even though the average shale used in the cement mix does not contain more than 1.5 to 2.5 per cent of potash $\left(\mathrm{K}_{2} \mathrm{O}\right)$, the potential supply from this source would be very great, as a result of the tremendous tonnage of cement being produced.

The Illinois shales that we are here considering, instead of having an average potash content of 2 or even 2.5 per cent, have a content of 5 per cent. They compare, therefore, very favorably with the greensands of New Jersey.2 The first question that naturally arises, therefore, relates to the suitability of these Illinois shales for the purpose of compounding a suitable cement mix.

Illinois shales of suitable composition for cement making, according to Bleininger, ${ }^{3}$ are shown in 'Table I. For comparison, two of the high potash shales are shown in parallel columns.

1 Presented before the Division of Fertilizer Chemistry at the 60th Meeting of the American Chemical Society, Chicago, Ill, September 6 to 10. 1920 .

2 Chem. Met. Eng., 22 (1920), 815

8 Illinois State Geological Survey, Bulletin 17 (1912).

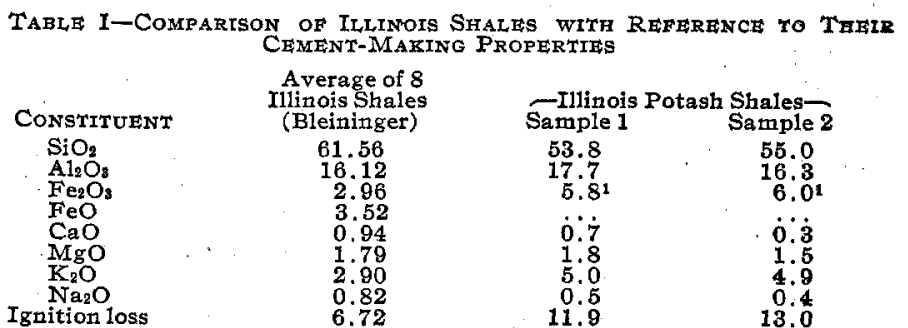

1 Total iron calculated to $\mathrm{Fe}_{2} \mathrm{O}_{3}$.

Samples 1 and 2 are the black carbonaceous shale from Union County. It will be observed that, except in potash content, they vary but little in composition from the average of other shales which are said to be suitable for cement making. Their high potash content might be an advantage also in the formation of the clinker, since it would tend to lower the burning temperature.

Other factors which are important in evaluating these shales for cement-making purposes are as follows:

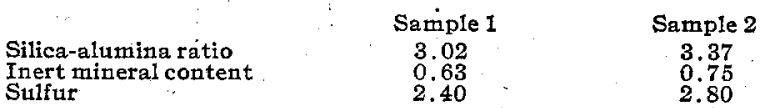

The silica-alumina ratio is in the most advantageous zone, and the inert mineral content is low. The sulfur occurs principally in microscopic form as pyrite.

In average American practice the raw mix will contain 0.7 to 1.0 per cent of $K_{2} \mathrm{O}$. On the basis of 65 per cent recovery, which according to Huber and Reath ${ }^{1}$ it seems reasonable to expect, there would result an average yield of $2.9 \mathrm{lbs}$. of potash per barrel of cement. On the same basis, the potash shales whose analyses are given in Table I should yield 5.4 lbs. per bbl.

One other region in the state has thus far supplied a shale with a high potash content, but its cement-making possibilities have not been determined. This shale, from Dixon, in Lee County, contains 5.8 per cent of potash. It is coarsegrained and friable. While its green color is suggestive of the greensands of the East, the geological character of the material is quite different, as will be shown later.

\section{Constitumion of Illinors Potash Shales}

The shales from Union County are peculiar in that they contain a small percentage of oil, present in the free state. This has no industrial significance, but it adds to the other volatile constituents, such as water of hydration, so that the reduction in weight upon ignition, as shown in Table $I$,

1 Chem. Met. Eng., 16 (1917), 702. 